PREPARED FOR THE U.S. DEPARTMENT OF ENERGY, UNDER CONTRACT DE-AC02-76CH03073

PPPL-3866

PPPL-3866

UC-70

Development of an Electrostatic Dust Detector for use in a Tokamak Reactor

by

A. Bader, C.H. Skinner, A.L. Roquemore, and S. Langish

September 2003

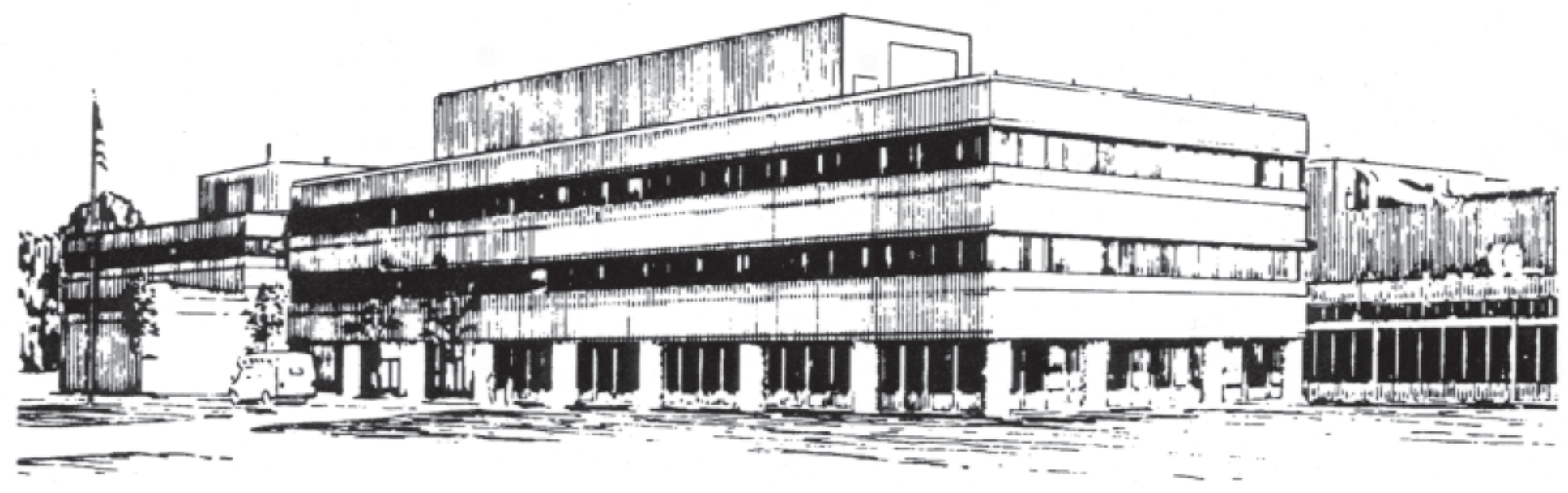

PRINCETON PLASMA PHYSICS LABORATORY PRINCETON UNIVERSITY, PRINCETON, NEW JERSEY 


\section{PPPL Reports Disclaimer}

This report was prepared as an account of work sponsored by an agency of the United States Government. Neither the United States Government nor any agency thereof, nor any of their employees, makes any warranty, express or implied, or assumes any legal liability or responsibility for the accuracy, completeness, or usefulness of any information, apparatus, product, or process disclosed, or represents that its use would not infringe privately owned rights. Reference herein to any specific commercial product, process, or service by trade name, trademark, manufacturer, or otherwise, does not necessarily constitute or imply its endorsement, recommendation, or favoring by the United States Government or any agency thereof. The views and opinions of authors expressed herein do not necessarily state or reflect those of the United States Government or any agency thereof.

\section{Availability}

This report is posted on the U.S. Department of Energy's Princeton Plasma Physics Laboratory Publications and Reports web site in Fiscal Year 2003. The home page for PPPL Reports and Publications is: http://www.pppl.gov/pub_report/

DOE and DOE Contractors can obtain copies of this report from:

U.S. Department of Energy

Office of Scientific and Technical Information

DOE Technical Information Services (DTIS)

P.O. Box 62

Oak Ridge, TN 37831

Telephone: (865) 576-8401

Fax: (865) 576-5728

Email: reports@adonis.osti.gov

This report is available to the general public from:

National Technical Information Service

U.S. Department of Commerce

5285 Port Royal Road

Springfield, VA 22161

Telephone: $1-800-553-6847$ or

(703) $605-6000$

Fax: (703) 321-8547

Internet: http://www.ntis.gov/ordering.htm 


\title{
Development of an Electrostatic Dust Detector for use in a Tokamak Reactor
}

\author{
A. Bader \\ ${ }^{a}$ The Cooper Union for the Advancement of Science and Art, New York, NY, 10003 \\ C. H. Skinner, A. L. Roquemore and S. Langish, \\ ${ }^{b}$ Princeton Plasma Physics Laboratory, Princeton, New Jersey, 08543
}

\begin{abstract}
Initial results from a novel device to detect dust particles settling on remote surfaces are presented. Dust particle inventories are a concern in next-step fusion devices. The increase in duty cycle will lead to a scale-up in the amount of particles generated by plasma material interactions. These particles will be chemically and radiologically hazardous and it will be important to establish that the in-vessel particle inventory is within regulatory limits. The detection device consists of two interlocking combs of closely spaced conductive traces on a Teflon circuit board. When a DC bias is applied impinging dust creates a transient short circuit between the traces. The increase in bias current generates a signal pulse that is counted by standard nuclear counting electronics. We present data on the response of the device in air and vacuum to carbon particles.
\end{abstract}




\section{INTRODUCTION}

Diagnosis and management of dust particles in tokamaks is a 'housekeeping' area that falls in-between traditional plasma diagnostics and plasma technology fields. However it is critical to the safe operation of next step devices. Particles produced from deposited layers by plasma erosion, ELMs and disruptions have been collected from current tokamaks during maintenance periods and analyzed. ${ }^{1-6}$ Dust has not been a noticeable problem so far in current fusion devices, however, in next step devices such as ITER, the increase in duty cycle and erosion levels will cause a large scale-up in the amount of particles produced and this has important safety consequences. ${ }^{7}$ Tokamak dust may be radioactive from tritium or activated metals, toxic and /or chemically reactive with steam or air. The large surface area associated with dust can greatly amplify its chemical reactivity. The in-vessel particle inventory must be regulated so it cannot create a serious hazard. For ITER to avoid the hazard of hydrogen explosions, the inventory of beryllium dust residing in the grooves of the tungsten divertor armor is limited to $10-20 \mathrm{~kg}$. A second limit is set at a few hundred $\mathrm{kg}$ for dust that could be mobilized during an accident and escape causing a radiological hazard. Tritiated dust becomes statically charged through the emission of beta electrons and this enhances its mobility. ${ }^{8}$ An ideal diagnostic would produce a complete spatial map of the areal density of dust and its particle size distribution throughout the tokamak in order to demonstrate compliance with the inventory limits. However, such a diagnostic does not exist. Measuring the particle inventory is a challenge in existing machines let alone one with the radiological environment and scale of ITER. ${ }^{9,10}$

We present initial results from tests of a novel device that detects dust on remote surfaces. Two closely interlocking grids of conductive traces on a circuit board are biased at a DC voltage. Impinging conductive particles create a transient short circuit and a current pulse that can be easily detected by standard nuclear counting electronics. We have tested the device in air and in a vacuum chamber using particles from an unused carbon fiber composite (CFC) tokamak tile. Because of its electrostatic operating principle, this device does not provide an absolute measure of the areal density of dust - such a diagnostic still needs to be developed. However some correlation between recorded counts and particle concentration 
was found. The present detector could be used for time resolved measurements in existing machines to identify scenarios that lead to the generation of dust. For next-step devices, an array of detectors could be inexpensively installed over wide areas so that, in conjunction with quantitative dust mass diagnostics (still to be developed), they could improve confidence that dust inventory limits were not exceeded. This device could be applied to any situation where information on the presence of electrically conductive dust on hard-to-access areas was important.

\section{ELECTROSTATIC DUST PARTICLE DETECTION DEVICE.}

Standard circuit board technology was used to deposit a grid of interlocking traces on a circuit board. The boards were made of $0.56 \mathrm{~mm}$ thick Teflon substrate with rolled 1-ounce copper. After etching the desired pattern of traces, tin plating 4-6 micron thick was applied over the copper by the immersion process. Various trace widths and spacings were used. The traces were 127 or $254 \mu \mathrm{m}$ wide, separated by distances of $127 \mu \mathrm{m}$ (minimum available) to $762 \mu \mathrm{m}$ and covering an area of $1.2 \times 1.2 \mathrm{~cm}$ (figure 1). In the absence of dust, the circuit could stand off a voltage of more than 800 volts (figure 2). To simulate the effect of dust the grids were tested with particles scraped from a CFC tile. Samples of the particles were coated with $2 \mathrm{~nm}$ of iridium and examined with a Philips XL30 FEG Scanning Electron Microscope (SEM) (figure 3). These particles typically had a cylindrical shape of length $10-500 \mu \mathrm{m}$ and diameter $1-20 \mu \mathrm{m}$ as seen in the SEM image. We also imaged the carbon particles with a digital microscope at 40x magnification and analyzed the mean particle size with NIH Image software. The imaged particles had a mean projected area of $325 \mu^{2}$ with a standard deviation of $805 \mu \mathrm{m}^{2}$. Figure 4 shows a histogram of the distribution of the surface area. While some of the particles are capable of bridging the gap between the traces on the grid, most are smaller than the intertrace distance and two or more adjoining particles would be needed to create a short circuit. We also obtained commercially available carbon powder consisting of spherical particles with a nominal diameter of 12 microns. However the powder stuck together in clumps and it was difficult to disperse and deliver in a dust-like manner.

Miniature sparks appeared when particles landed on the energized grid and created a short circuit. Typically the particles vaporized in a few seconds restoring the previous voltage 
standoff. However, large quantities of particles could create a continuous short. In order to detect these events routinely at remote locations, a circuit was constructed as shown in figure 5. A Kepco ATE-325 (0-200 V and 0-0.8 A) variable power supply provided the bias voltage. A voltage divider across the output provided a convenient monitor of the output voltage. A short circuit, created by impinging dust particles caused current to flow in the $51 \Omega$ resistor. The resulting signal exhibited low and high frequency fluctuations and in some cases a continuing DC voltage signal if the particle was not completely vaporized. The signal was conditioned by high pass and low pass RC filters with a band pass of $1.6 \mathrm{~Hz}-25 \mathrm{kHz}$ to produce a waveform suitable for the counting electronics. The filtered signal was input to an Ortec 550 Single Channel Analyzer (SCA) which produced an output pulse every time the input signal decreased past a level of $400 \mathrm{mV}$ and these pulses were counted by an Ortec 775

Counter (1 - 999,999 range). Waveforms of the signal created from impinging dust were recorded by a Tektronix TDS 3054 Digital Oscilloscope, and an example is presented in figure 6 together with the resulting output pulses from the Single Channel Analyzer.

\section{EXPERIMENTAL SET UP FOR PARTICLE DETECTION ON SURFACE IN AIR}

The circuit board with the grids was mounted $2 \mathrm{~cm}$ high in the center of a $35 \mathrm{~cm}$ by 25 $\mathrm{cm}$ by $7.5 \mathrm{~cm}$ deep aluminum box. A $2.5 \mathrm{~cm}$ diameter pipe was used to deliver a controlled amount of particles to the area of the grid in as uniform a distribution as possible and is shown in figure 7. A horizontal $10.5 \mathrm{~cm}$ long pipe had a $7 \mathrm{~mm}$ diameter hole for introducing a preweighed amount of particles. This was joined by an elbow to an $18 \mathrm{~cm}$ long vertical pipe positioned $6 \mathrm{~cm}$ over the grid. A $10 \mathrm{scc} / \mathrm{min}$ nitrogen stream was introduced through a tube 3 $\mathrm{cm}$ behind the access hole. This arrangement deposited particles over a circular area with diameter of $10 \mathrm{~cm}$ centered on the grid without any pronounced clumping or non-uniformity on the grid.

To estimate the amount of dust incident on the grid area a collection bin of the same area as the grid was constructed of aluminum foil and placed over the grid. Small weights were used to prevent it from being displaced by the nitrogen flow. A Sartorius BP2215 balance with sensitivity $0.1 \mathrm{mg}$ was used to measure the delivery efficiency. A pre-weighed amount of dust was dropped through the access hole. The flow of nitrogen was stopped and 
the dust deposited in the aluminum foil bin was weighed. The bin and the surrounding area were cleaned with compressed gas after each measurement. The total mass of input particles ranged from $20 \mathrm{mg}$ to $80 \mathrm{mg}$ (the maximum used in the subsequent experiments). It was found that the fraction of particles deposited in the bin ranged from 2-4\% with a mean of $2.9 \%$ and a standard deviation of $0.8 \%$ (figure 8 ). While we used much smaller amounts of dust than $20 \mathrm{mg}$ in the subsequent experiment, the delivery efficiency could not be accurately measured because of the small fraction of dust that landed in the bin and it was assumed that the linear behavior shown in figure 8 continued to lower masses.

Dust particles could be easily detected at voltages much lower than the breakdown voltage and in most cases the particles vaporized terminating the short circuit. At voltages lower than $30 \mathrm{~V}$ the response became more variable with continuous short circuits remaining more frequently. Therefore, an operating point at $30 \mathrm{~V}$ was chosen. The response of grids with different spacings to incident particles was measured. A measured amount of dust was introduced and the counts were accumulated for 10 seconds. Often a few seconds would elapse before the first count was registered. In almost all cases counts continued throughout the timing because the constant airflow through the pipe caused motion of the particles on the grid. After 10 seconds a jet of compressed gas was used to clean the wire grid and the surrounding area. The experiment was repeated several times with varying amounts of dust particles for each grid.

\section{RESULTS FROM OPERATION IN AIR}

The results showed that as the spacing of the grid increases, the detector becomes less sensitive to dust but can also provide readings of larger amounts of particles without a continuous short circuit. The results for each grid are presented in figure 9 together with a second order polynomial fit with intercepts at the origin (higher order curves did not provide a significant increase in the correlation coefficient). For the smaller grid spacings there is a reasonable correlation between the mass of dust and the counts. However, as the grid spacing increase, the correlation between counts and amount of dust becomes more tenuous. There are two significant sources of irreproducibility. One is the variation in the amount of dust delivered to the grid (figure 8) and is represented in the horizontal error bars. This error is 
random and is independent of the amount of dust blown. The second is caused by the relative size and orientation of the particles compared to the grid spacing. Larger grid spacings require several aligned particles to bridge the gap and create a short circuit and this introduces some statistical variation in the response.

Another important aspect was the resiliency of the grids. Each grid was in operation for at least 5 hours and during that time was subjected to approximately 100 short circuits, occurring at voltages mostly around $30 \mathrm{~V}$ but also at values up to $200 \mathrm{~V}$ and currents up to 0.2 A. For these conditions there was no damage to the grids and the Teflon board with the exception of a darkening of color. At all times the short circuits were terminated when the grids were blown clean with compressed gas.

\section{PARTICLE DETECTION ON SURFACE IN VACUUM}

Dust detection on surfaces in vacuum is required for applications such as next-step tokamaks. To test the vacuum performance the circuit board was mounted inside a vacuum vessel using ceramic standoffs on a stainless steel sheet metal base. The base was attached to the vessel by two sheet metal tabs that had been welded on to the vessel walls to enable adjustment of the grid position. Between 0.3 and $0.7 \mathrm{~g}$ of particles were placed in a trough covered with a wire screen with $550 \mu \mathrm{m}$ square holes. After pump down to below $10 \mu$ torr, the trough was inverted over the grid by a rotary feedthrough (figure 10). A window directly above the grid enabled visual observation of effect of the impinging dust. Because of the time required to cycle the vacuum system for each condition this dataset is not as extensive as in the air case.

Smaller impinging particles created a brief bright spark. Larger particles and clumps of carbon dust were observed to incandesce. Increasing the voltage caused incandescent particles to increase in brightness and at currents over $0.2 \mathrm{~A}$, these could melt the traces on the circuit board after about a minute. The particle would emit a bright spark and vaporize at a voltage dependent on the particle size. The largest particles that were able to pass through the wire screen were observed to vaporize at voltages between 35 and $40 \mathrm{~V}$. 
The areal concentration of impinging particles was determined in a method similar to that used for the experiment in air. An aluminum collection bin was placed over the grid and the rotary feed through was rotated 10 times in a vacuum with pressure between 1 and 10 $\mu$ torr. With between 300 and $700 \mathrm{mg}$ of carbon particles initially present in the rotary trough, 10 rotations deposited $0.7 \mathrm{mg}$ of particles in the bin. In this range the amount of particles deposited in the bin was independent of the amount of particles in the trough. It was extrapolated that, on average, $0.07 \mathrm{mg}$ were deposited on the grid per revolution.

Each grid was tested with the same electronic circuitry as the air experiment (figure 5). The DC bias was increased from $30 \mathrm{v}$ to $50 \mathrm{~V}$ to vaporize incandescent particles and current limited to less than $200 \mathrm{~mA}$ to avoid damage to the traces. The rotary feed through was rotated 10 times and the resulting counts were registered by the SCA after each successive rotation and deposition of particles on the grid. The fluctuation in the counts recorded from each deposition was larger than experienced in the air configuration of section III. Since the weight of the average deposition $(0.07 \mathrm{mg})$ from one rotation is beyond the resolution of the balance it is not clear how much of this fluctuation is due to variations in the particles delivered on each rotation. Figure 11 shows the results and table 2 the statistical properties of the counts obtained for all ten rotations for each grid. There are other significant configuration differences between the air and vacuum setup. In the vacuum configuration, 10 deliveries of particles accumulate on the grid, compared to air configuration where the particles are carried in the nitrogen stream and each measurement is followed by particle blow off by compressed gas. Also the mesh in the vacuum setup could filter out the largest particles. To identify differences between operation in air and vacuum, the vacuum experimental configuration was also operated in the presence of air at atmospheric pressure. The number of recorded counts increased significantly as shown in table 2, apparently due to the increased high frequency fluctuations in the waveform in air. For application to different environments and dust particle size distributions, calibration of the response will be key for quantitative interpretation of the results beyond a simple detection of particles. 


\section{V.SUMMARY.}

Initial tests of a device to detect dust on remote surfaces showed that carbon particles could be detected on surfaces in vacuum and air environments. The short circuit created by the particle was usually transient with the particles oxidizing (in air) or subliming by the electrical heating $(50 \mathrm{~V},<0.2 \mathrm{~A})$ in vacuum so the detector was able to reset and detect particles continuously. The detection threshold in air was below $50 \mu \mathrm{g} / \mathrm{cm}^{2}$ for the finest $(127$ $\mu \mathrm{m})$ grid spacing $\left(34 \mu \mathrm{g} / \mathrm{cm}^{2}\right.$ gave 25 counts). The detection threshold for the vacuum configuration appeared to be somewhat higher. The upper detection limit for each grid was determined by a large quantity of particles creating a continuous short circuit. For the coarsest grid (762 $\mu \mathrm{m}$ spacing) this limit was above $1.6 \mathrm{mg} / \mathrm{cm}^{2}$. There was a correlation between particle concentration and recorded counts for fine grid spacings. Grids of differing spacing can be combined to extend the dynamic range of the device. In vacuum $50 \mathrm{~V}$ bias voltage was needed to vaporize the particles while $30 \mathrm{~V}$ was sufficient in air. These results show promise for the detection of dust particles on remote surfaces and tests and calibrations inside the NSTX tokamak are planned.

\section{ACKNOWLEDGEMENTS}

The authors thank G. Gibilisco, T. Holoman, H. Schneider, D. LaBrie, L. Ciebiera and M. Dimattia for technical assistance. A. Bader acknowledges support from the 2003 National Undergraduate Fellowships in Plasma Physics and Fusion Energy Sciences. The detailed drawing of the circuit board was by Advanced Technology Laboratories Inc. and fabrication by Fineline Circuits, both of Feasterville, PA. This work was funded by U.S. DOE Contract Nos. DE-AC02-76CH0307.

\section{REFERENCES}

1 W. J. Carmack, R. A. Anderl, R. J. Pawelko, G. R. Smollik, K. A. McCarthy, Fusion Eng. Des., 51-2: 477-484 (2000).

2 J. Winter, Plasma Phys. Control Fusion, 40, 1201 (1998). 
A. T. Peacock, P. Andrew, P. Cetier, J. P. Coad, G. Federici, F. H. Hurd, M. A. Pick, C. H. Wu, J. Nucl. Mater., 266-269, 423 (1999).

Ph. Chappuis, E. Tsitrone, M. Mayne, X. Armand, H. Linke, H. Bolt, D. Petti, J.P. Sharpe, J. Nucl. Mater., 290 - 293, 245 (2001).

5 M. Rubel, M. Cecconello, J. A. Malmberg, G. Sergienko, W. Biel, J. R. Drake, A. Hedqvist, A. Huber, V. Philipps, Nucl. Fus., 41, 1087, (2001).

6 J. P. Sharpe, P.W. Humrickhouse, C. H. Skinner, "Dust Collection and Analysis for NSTX- June 2002 Vent", Idaho National Engineering and Environmental Laboratory external report no.: INEEL/EXT-03-01083.

7 G. Federici, C. H. Skinner, J. N. Brooks, J. P. Coad, C. Grisolia, A. A. Haasz, A. Hassanein, V. Philipps, C. S. Pitcher, J. Roth, W. R. Wampler, D. G. Whyte, Nucl. Fus., 41, 1967 (2001).

8 C. H. Skinner, C. A. Gentile, L. Ciebiera, S. Langish, Fus. Sci. \& Technol. in press (2003).

$9 \quad$ G. F. Counsell and C. H. Wu, Phys. Scripta., TIC116, 1 (2001).

10 G.T. Razdobarin, G. Federici, V.M. Kozhevin, E.E. Mukhin, V.V. Semenov, S.Y. Tolstyakov, Fus. Sci. \& Technol., 41, 32-43 (2002). 


\section{LIST OF TABLES:}

TABLE 1: Width and spacing of the 5 grids used and average counts recorded in response to differing concentrations of incident particles in air. Dashed lines indicate that no measurements were taken in this range. Measurements were not taken above a certain level because the particle concentration caused a short circuit.

Table 2: Vacuum chamber results. Statistical values of counts for 10 rotations in vacuum; and with atmospheric pressure air in the vacuum chamber. 


\section{LIST OF FIGURES:}

Figure 1. Schematic of T3 circuit; trace width $254 \mu \mathrm{m}$, spacing 381 microns, overall area $1.2 \mathrm{x}$ $1.2 \mathrm{~cm}$ (not to scale).

Figure 2. Plot of breakdown voltages of circuit board without particles present.

Figure 3. Scanning Electron Microscope images of particles scraped from a CFC tile, $(100 \mu \mathrm{m}$ and $20 \mu \mathrm{m}$ scale-bar).

Figure 4. Histogram of particle size distribution of CFC particles with surface area less than $1000 \mu \mathrm{m}^{2}$ area. Data was obtained with a digital microscope at 40x resolution. Particles with area less than $5 \mu \mathrm{m}^{2}$ were beyond the resolution of the microscope.

Figure 5. Circuit diagram including power supply, high pass and low pass filters, oscilloscope, single channel analyzer and counter.

Figure 6. Typical waveforms of the signal created by approximately $0.3 \mathrm{mg}$ of impinging particles on grid $\mathrm{T} 4$ with a bias voltage of $50 \mathrm{~V}$ in air. The uppermost waveform is the unfiltered signal; the waveform directly below it is the signal after it passed through the band pass filters (Y-axis scale on left). The lowermost waveform is the signal from the single channel analyzer (SCA) and corresponding Y-axis scale is on the right. Also shown is a dotted line indicating $0.4 \mathrm{~V}$. The SCA was set to trigger on the falling edges of pulses at $0.4 \mathrm{~V}$.

Figure 7. Particle delivery system for experiments in air. The dimensions are in $\mathrm{cm}$.

Figure 8. Plot of the amount of dust that was found to land within a bin corresponding to grid size as a function of the dust blown through the pipe. The dashed lines represent lines measuring $1.9 \%$ and $3.9 \%$ values. The error bars of $\pm 0.1 \mathrm{mg}$ represent the resolution of the balance.

Figure 9. Counts versus the areal density of dust on grids T1-T5. The line is a second order polynomial curve fit to the data. Horizontal error bars represent \pm 1 standard deviation uncertainty in the particle concentration on the grid.

Figure 10. Particle delivery system for experiments in vacuum.

Figure 11. Vacuum results. Cumulative counts from successive deliveries of particles to grids $\mathrm{T} 1$ - T5. The lines are intended as a visual aid. 
TABLE 1: Width and spacing of the 5 grids used and average counts recorded in response to differing concentrations of incident particles in air. Dashed lines indicate that no measurements were taken in this range. Measurements were not taken above a certain level because the particle concentration caused a short circuit.

\begin{tabular}{cccccc}
\hline \multicolumn{7}{c}{ Particle detection in air configuration } & & \\
\hline Grid: & T1 & T2 & T3 & T4 & T5 \\
\hline $\begin{array}{c}\text { Trace width } \\
(\mu \mathrm{m})\end{array}$ & 127 & 254 & 254 & 254 & 254 \\
Spacing $(\mu \mathrm{m})$ & 127 & 254 & 381 & 508 & 762 \\
\hline $\mathbf{m g} / \mathbf{c m}^{2}$ & counts & counts & counts & counts & counts \\
$0-0.05$ & 16 & -- & -- & -- & -- \\
$0.05-0.1$ & 111 & 7 & 0 & -- & -- \\
$0.1-0.2$ & 334 & 223 & 24 & 13 & -- \\
$0.2-0.4$ & 2672 & 1078 & 246 & 138 & 0 \\
$0.4-0.6$ & -- & 4085 & 2691 & 312 & 13 \\
$0.6-0.8$ & -- & -- & 2800 & 2927 & 245 \\
$0.8-1.2$ & -- & -- & -- & 3547 & 534 \\
$1.2-1.6$ & -- & -- & -- & -- & 728 \\
\hline \hline
\end{tabular}


Table 2: Vacuum chamber results. Statistical values of counts for 10 rotations in vacuum; and with atmospheric pressure air in the vacuum chamber.

\begin{tabular}{cccccc}
\hline \hline \multicolumn{5}{c}{ Particle detection in vacuum configuration } & \\
\hline Grid & T1 & T2 & T3 & T4 & T5 \\
Spacing $(\mu \mathrm{m})$ & 127 & 254 & 381 & 508 & 762 \\
Mean in vacuum & 54.4 & 74.7 & 59.1 & 15.5 & 4.9 \\
Median in vacuum & 24 & 49 & 34 & 4 & 0 \\
Std dev in vacuum & 70.3 & 66.5 & 69.8 & 32.1 & 8.9 \\
\hline Mean in air & 1090 & 446 & 397 & 185 & 140 \\
Median in air & 535 & 323 & 398 & 124 & 99 \\
Std. dev. in air & 1650 & 496 & 308 & 219 & 146 \\
\hline \hline
\end{tabular}




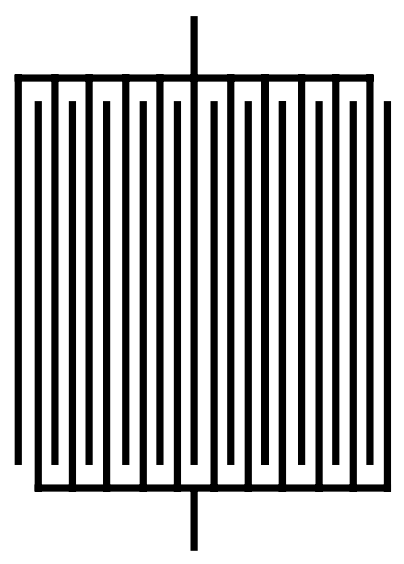

Figure 1 Schematic of T3 circuit; trace width $254 \mu \mathrm{m}$, spacing 381 microns, overall area $1.2 \mathrm{x}$ $1.2 \mathrm{~cm}$ (not to scale). 


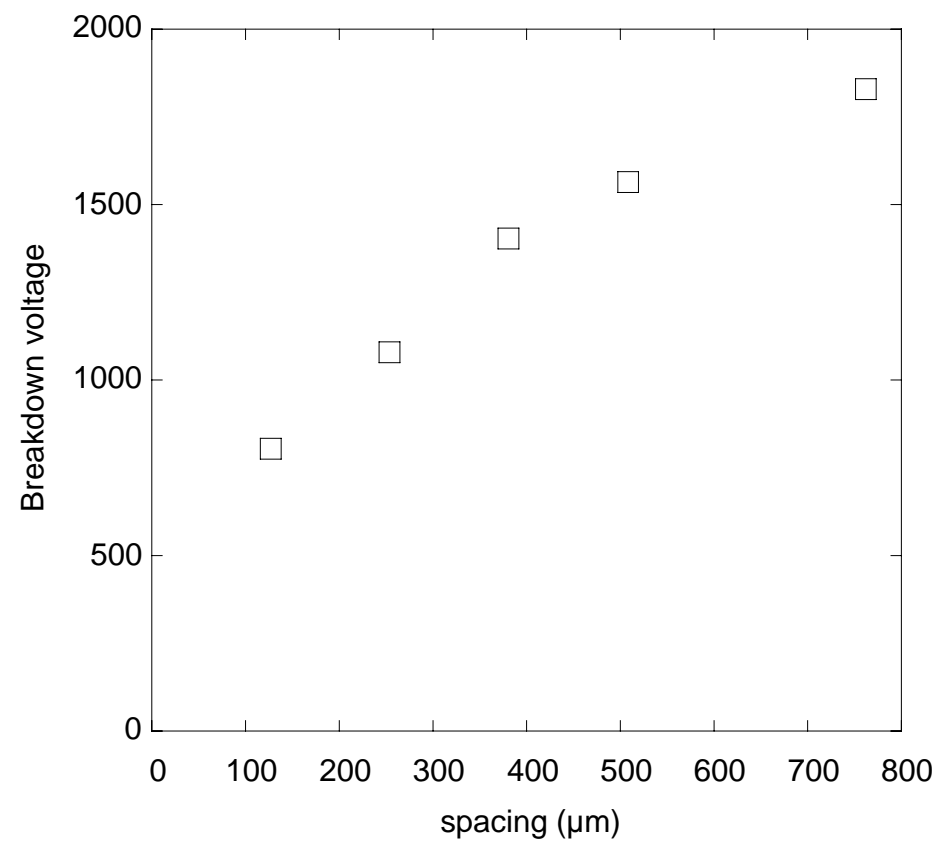

Figure 2. Plot of breakdown voltages of circuit board without particles present. 

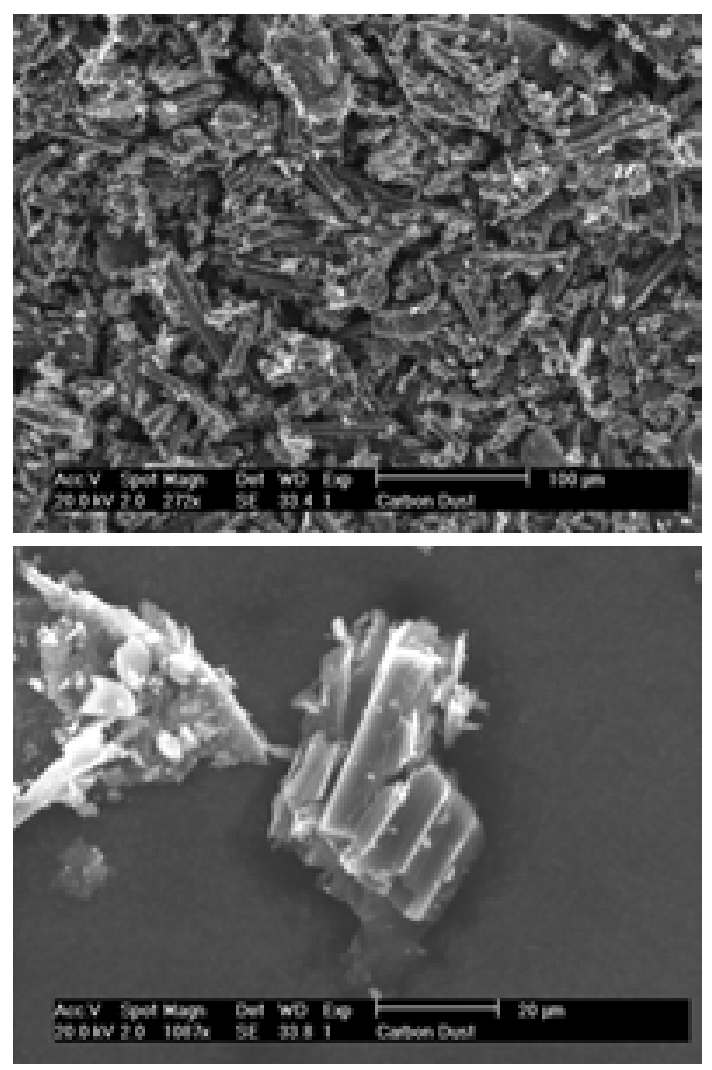

Figure 3. Scanning Electron Microscope images of particles scraped from a CFC tile, (100 $\mu \mathrm{m}$ and $20 \mu \mathrm{m}$ scale-bar). 


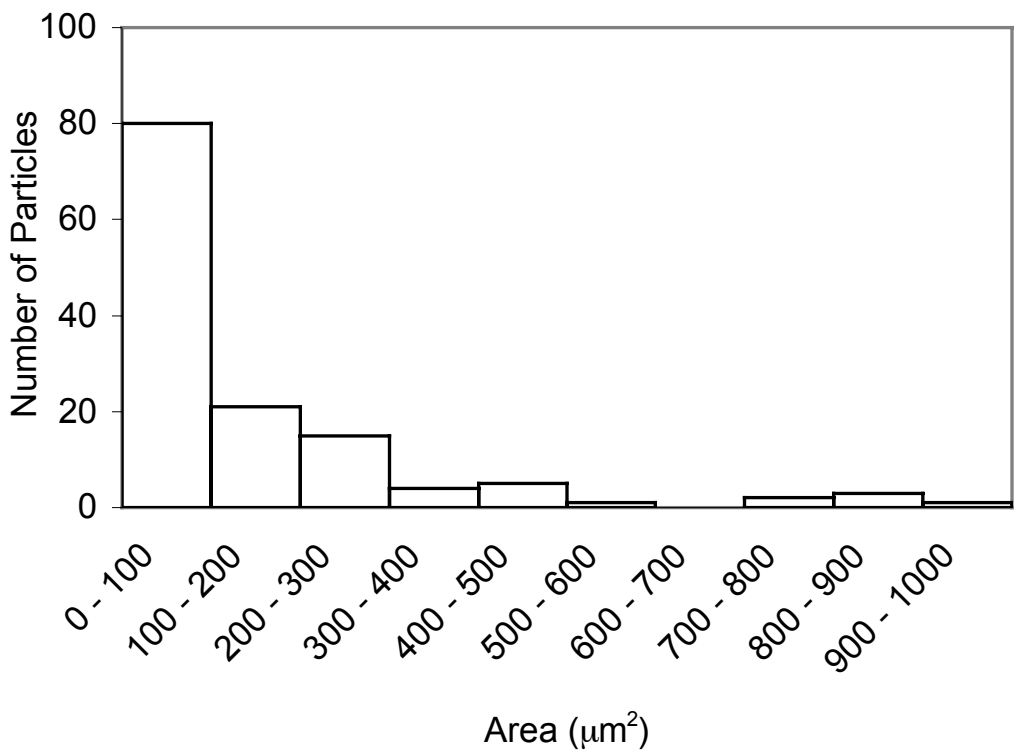

Figure 4. Histogram of particle size distribution of CFC particles with surface area less than $1000 \mu \mathrm{m}^{2}$ area. Data was obtained with a digital microscope at 40x resolution. Particles with area less than $5 \mu \mathrm{m}^{2}$ were beyond the resolution of the microscope. 


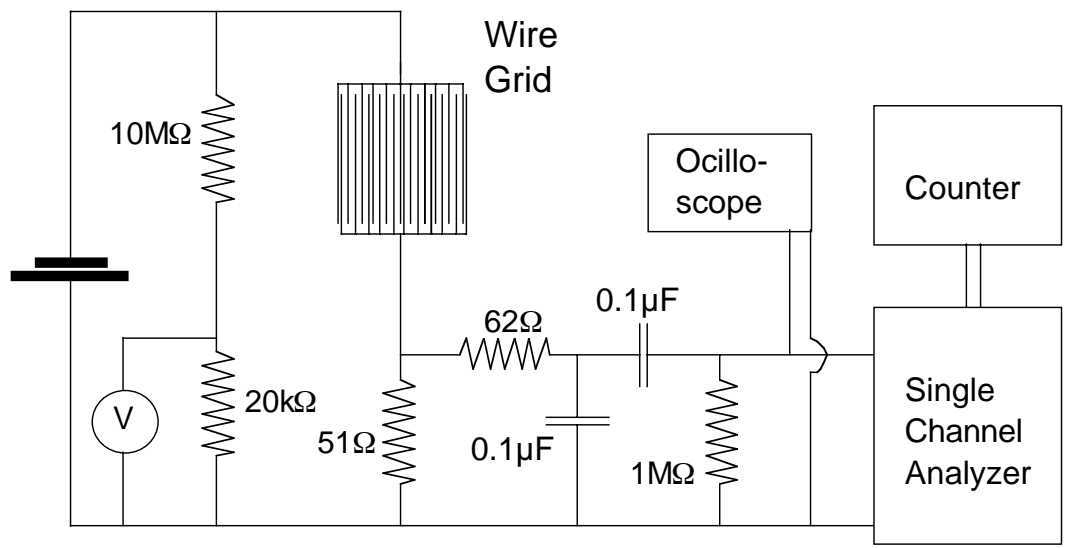

Figure 5. Circuit diagram including power supply, high pass and low pass filters, oscilloscope, single channel analyzer and counter. 


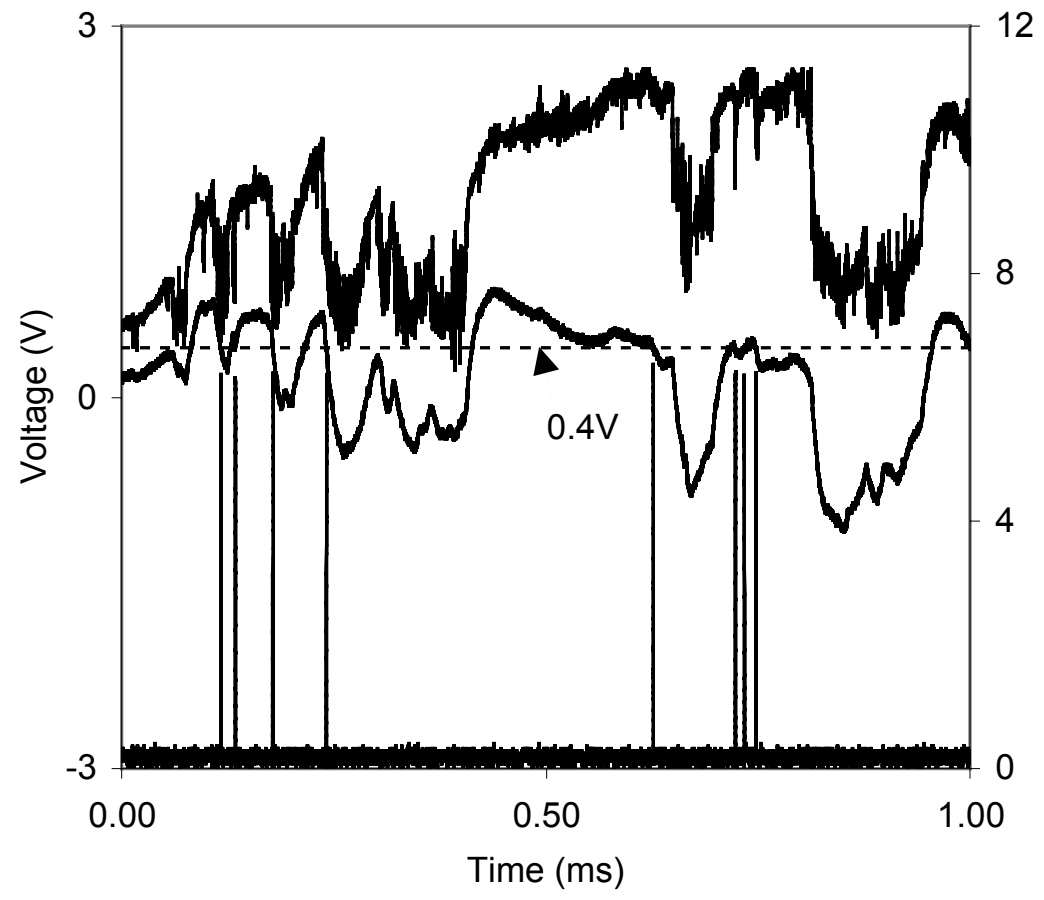

Figure 6. Typical waveforms of the signal created by approximately $0.3 \mathrm{mg}$ of impinging particles on grid $\mathrm{T} 4$ with a bias voltage of $50 \mathrm{~V}$ in air. The uppermost waveform is the unfiltered signal, the waveform directly below it is the signal after it passed through the band pass filters (Y-axis scale on left). The lowermost waveform is the signal from the single channel analyzer (SCA) and corresponding Y-axis scale is on the right. Also shown is a dotted line indicating $0.4 \mathrm{~V}$. The SCA was set to trigger on the falling edges of pulses at $0.4 \mathrm{~V}$. 


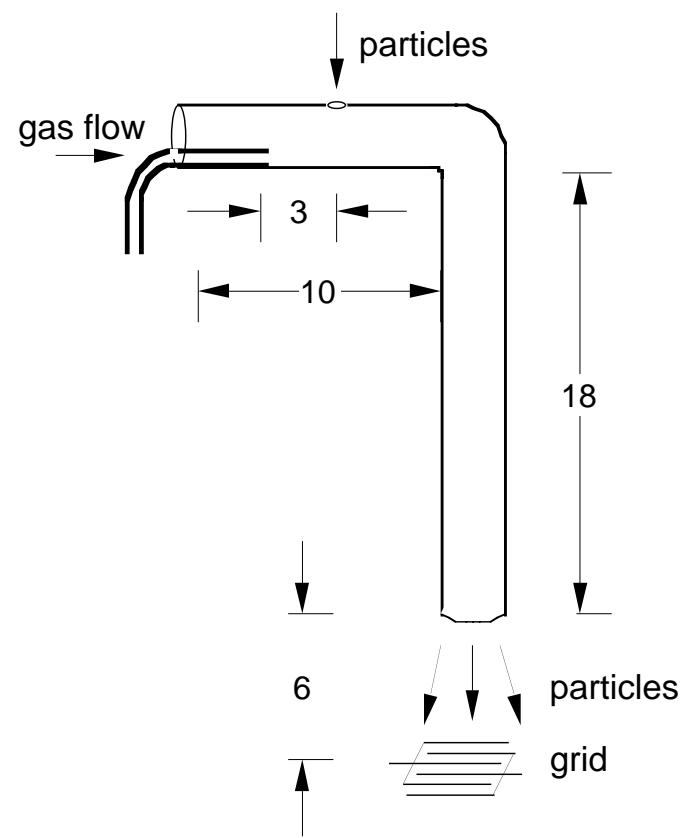

Figure 7 Particle delivery system for experiments in air. The dimensions are in $\mathrm{cm}$. 


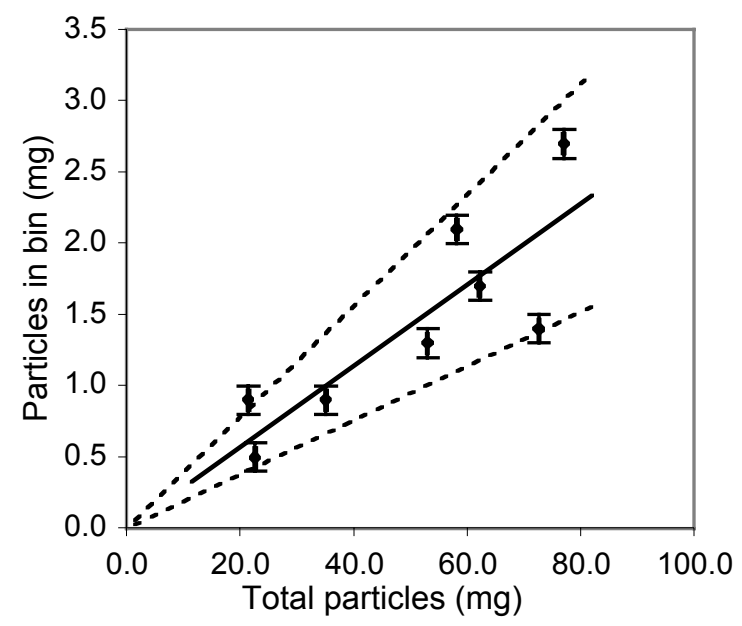

Figure 8. Plot of the amount of dust that was found to land within a bin corresponding to grid size as a function of the dust blown through the pipe. The dashed lines represent lines measuring $1.9 \%$ and $3.9 \%$ values. The error bars of $\pm 0.1 \mathrm{mg}$ represent the resolution of the balance. 


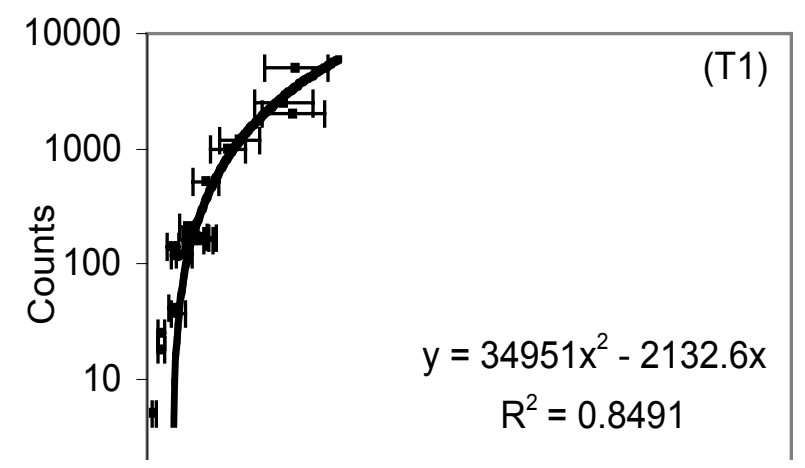

Figure 9 Air results. Counts versus the areal density of dust on grids T1-T5. The line is a second order polynomial curve fit to the data. Horizontal error bars represent \pm 1 standard deviation uncertainty in the particle concentration on the grid.
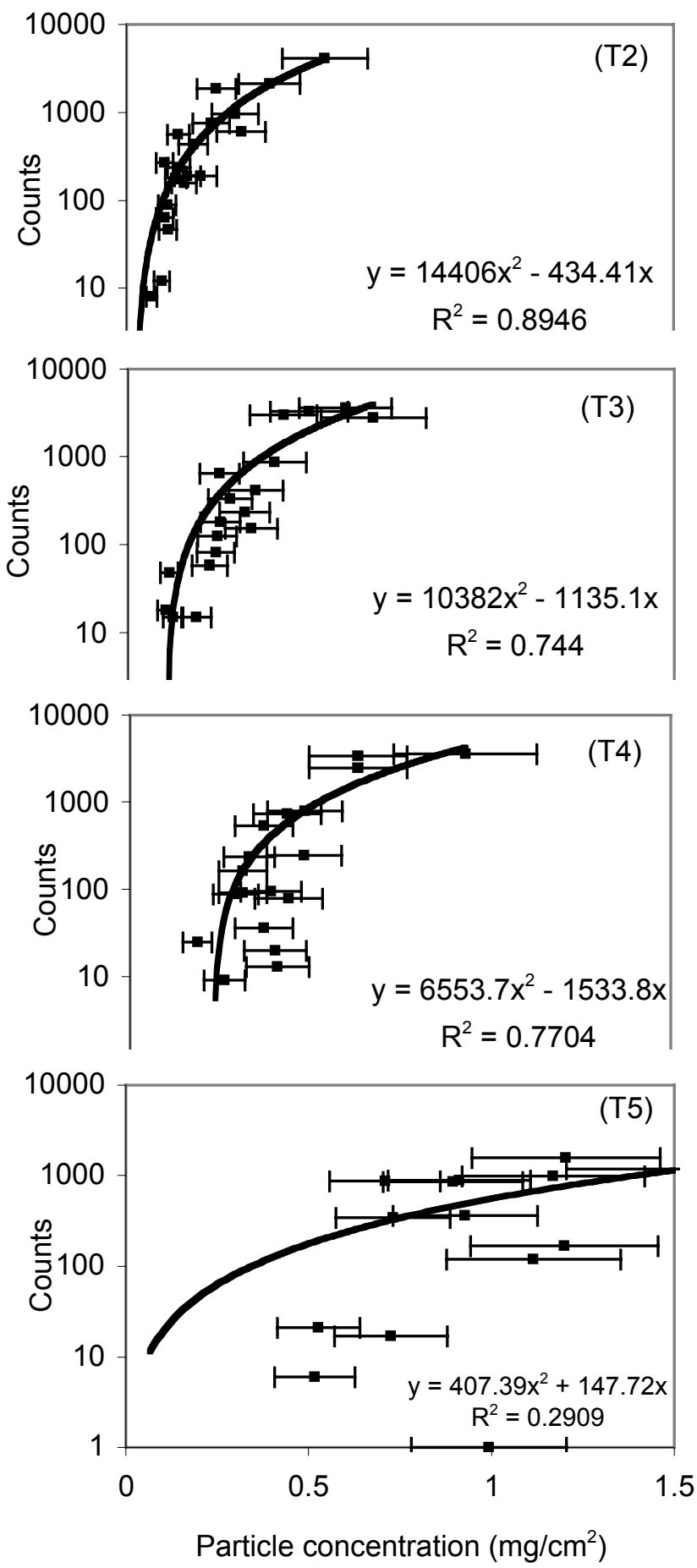


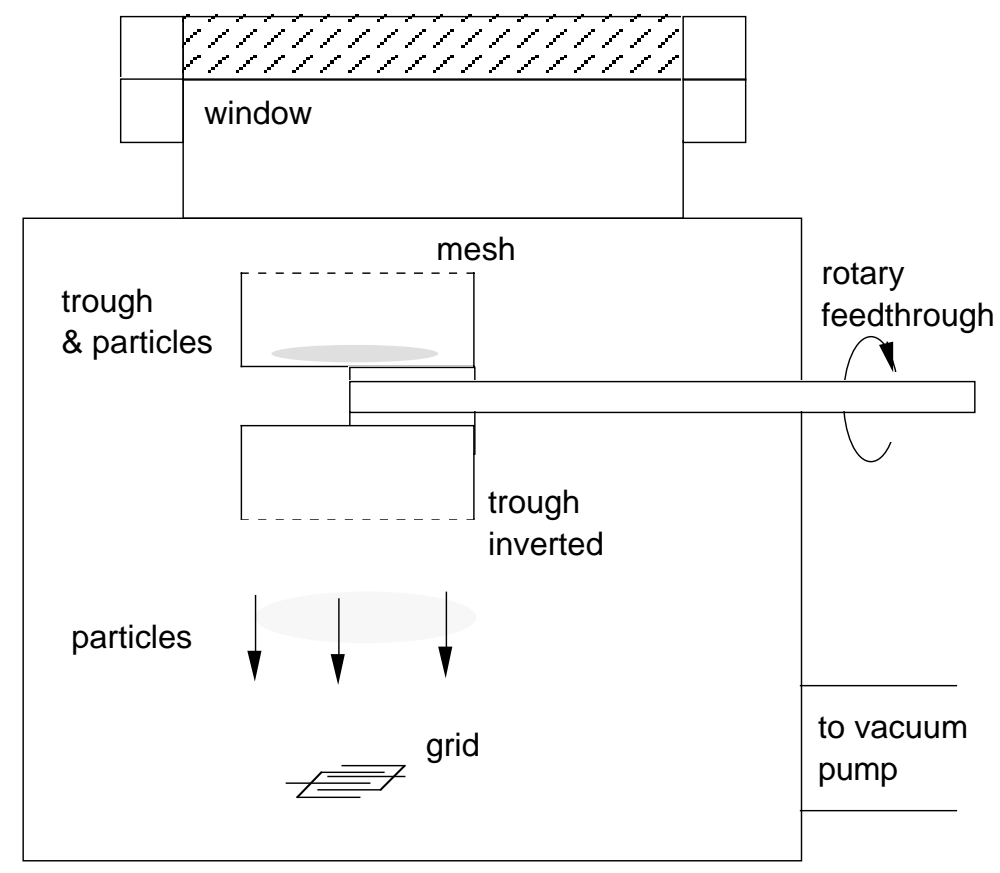

Figure 10. Particle delivery system for experiments in vacuum. 


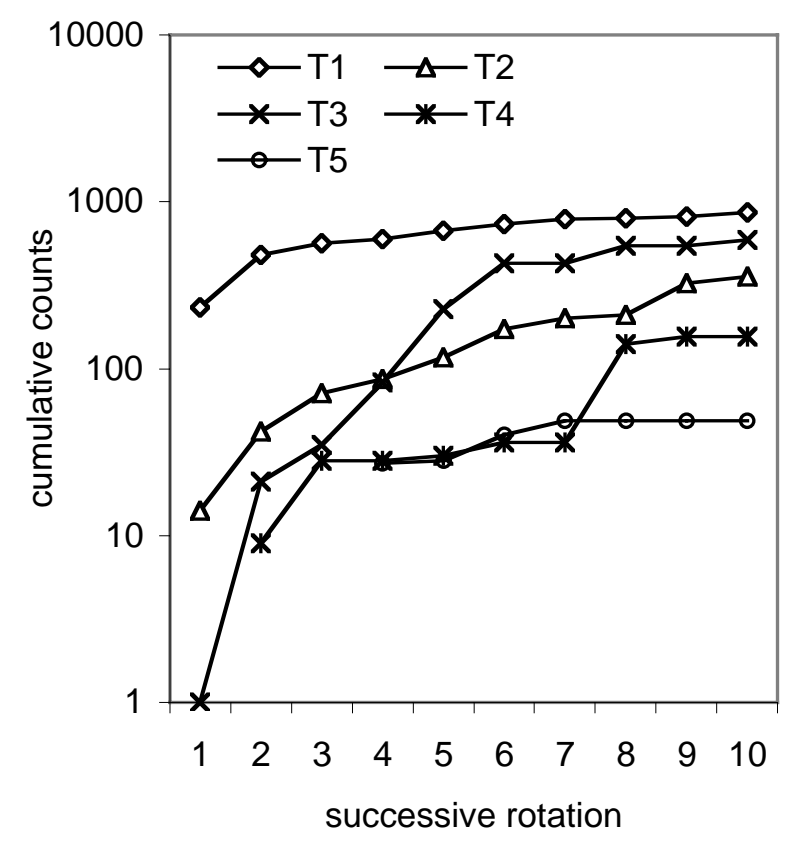

Figure 11. Vacuum results. Cumulative counts from successive deliveries of particles to grids T1 - T5. The lines are intended as a visual aid. 


\section{External Distribution}

Plasma Research Laboratory, Australian National University, Australia

Professor I.R. Jones, Flinders University, Australia

Professor João Canalle, Instituto de Fisica DEQ/IF - UERJ, Brazil

Mr. Gerson O. Ludwig, Instituto Nacional de Pesquisas, Brazil

Dr. P.H. Sakanaka, Instituto Fisica, Brazil

The Librarian, Culham Laboratory, England

Mrs. S.A. Hutchinson, JET Library, England

Professor M.N. Bussac, Ecole Polytechnique, France

Librarian, Max-Planck-Institut für Plasmaphysik, Germany

Jolan Moldvai, Reports Library, Hungarian Academy of Sciences, Central Research Institute for Physics, Hungary

Dr. P. Kaw, Institute for Plasma Research, India

Ms. P.J. Pathak, Librarian, Institute for Plasma Research, India

Ms. Clelia De Palo, Associazione EURATOM-ENEA, Italy

Dr. G. Grosso, Instituto di Fisica del Plasma, Italy

Librarian, Naka Fusion Research Establishment, JAERI, Japan

Library, Laboratory for Complex Energy Processes, Institute for Advanced Study, Kyoto University, Japan

Research Information Center, National Institute for Fusion Science, Japan

Dr. O. Mitarai, Kyushu Tokai University, Japan

Dr. Jiangang Li, Institute of Plasma Physics, Chinese Academy of Sciences, People's Republic of China

Professor Yuping Huo, School of Physical Science and Technology, People's Republic of China

Library, Academia Sinica, Institute of Plasma Physics, People's Republic of China

Librarian, Institute of Physics, Chinese Academy of Sciences, People's Republic of China

Dr. S. Mirnov, TRINITI, Troitsk, Russian Federation, Russia

Dr. V.S. Strelkov, Kurchatov Institute, Russian Federation, Russia

Professor Peter Lukac, Katedra Fyziky Plazmy MFF UK, Mlynska dolina F-2, Komenskeho Univerzita, SK-842 15 Bratislava, Slovakia

Dr. G.S. Lee, Korea Basic Science Institute, South Korea

Institute for Plasma Research, University of Maryland, USA

Librarian, Fusion Energy Division, Oak Ridge National Laboratory, USA

Librarian, Institute of Fusion Studies, University of Texas, USA

Librarian, Magnetic Fusion Program, Lawrence Livermore National Laboratory, USA

Library, General Atomics, USA

Plasma Physics Group, Fusion Energy Research Program, University of California at San Diego, USA

Plasma Physics Library, Columbia University, USA

Alkesh Punjabi, Center for Fusion Research and Training, Hampton University, USA

Dr. W.M. Stacey, Fusion Research Center, Georgia Institute of Technology, USA

Dr. John Willis, U.S. Department of Energy, Office of Fusion Energy Sciences, USA

Mr. Paul H. Wright, Indianapolis, Indiana, USA 
The Princeton Plasma Physics Laboratory is operated by Princeton University under contract with the U.S. Department of Energy.

\author{
Information Services \\ Princeton Plasma Physics Laboratory \\ P.O. Box 451 \\ Princeton, NJ 08543
}

Phone: 609-243-2750

Fax: 609-243-2751

e-mail: pppl_info@pppl.gov

Internet Address: http://www.pppl.gov 